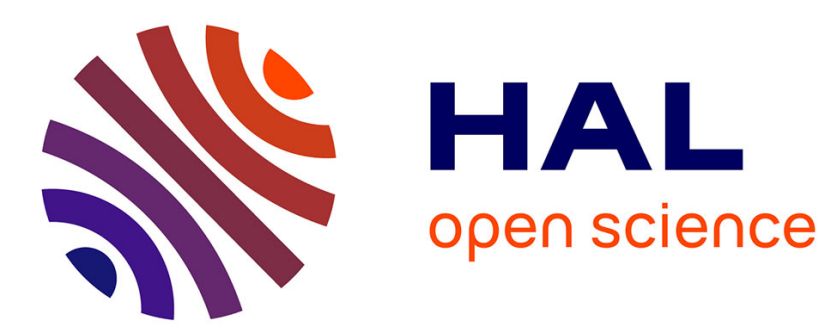

\title{
Polymer electrolyte membrane fuel cell fault diagnosis based on empirical mode decomposition
}

Cédric Damour, Michel Benne, Brigitte Grondin-Perez, Miloud Bessafi, Daniel Hissel, Jean-Pierre Chabriat

\section{- To cite this version:}

Cédric Damour, Michel Benne, Brigitte Grondin-Perez, Miloud Bessafi, Daniel Hissel, et al.. Polymer electrolyte membrane fuel cell fault diagnosis based on empirical mode decomposition. Journal of Power Sources, 2015, 299, pp.596-603. 10.1016/j.jpowsour.2015.09.041 . hal-01221973

\section{HAL Id: hal-01221973 \\ https://hal.univ-reunion.fr/hal-01221973}

Submitted on 26 Oct 2016

HAL is a multi-disciplinary open access archive for the deposit and dissemination of scientific research documents, whether they are published or not. The documents may come from teaching and research institutions in France or abroad, or from public or private research centers.
L'archive ouverte pluridisciplinaire HAL, est destinée au dépôt et à la diffusion de documents scientifiques de niveau recherche, publiés ou non, émanant des établissements d'enseignement et de recherche français ou étrangers, des laboratoires publics ou privés. 


\title{
Polymer electrolyte membrane fuel cell fault diagnosis based on empirical mode decomposition
}

\author{
Cédric Damour a, Michel Benne ${ }^{\text {a, }}{ }^{*}$, Brigitte Grondin-Perez ${ }^{a}$, Miloud Bessafi ${ }^{\text {a }}$, \\ Daniel Hissel ${ }^{b}$, Jean-Pierre Chabriat ${ }^{\mathrm{a}}$ \\ ${ }^{a}$ LE2P, EA 4079, University of La Reunion, 15 Av. René Cassin, BP 7151, 97715 Saint-Denis, France \\ ${ }^{\mathrm{b}}$ FCLAB Research Federation, FR CNRS 3539, FEMTO-ST/Energy Department, UMR CNRS 6174, University of Franche-Comté, Rue Thierry Mieg, 90010 Belfort \\ Cedex, France
}

\section{H I G H L I G H T S}

- An empirical, intuitive, self-adaptive non-model based diagnosis method is developed.

- Voltage measurements are decomposed in fourteen Intrinsic Mode Functions (IMFs).

- IMFs energy contributions are used to diagnosis healthy, flooding and drying states.

- The diagnosis is performed without any excitation signal or stabilization period.

\begin{abstract}
A B S T R A C T
Diagnosis tool for water management is relevant to improve the reliability and lifetime of polymer electrolyte membrane fuel cells (PEMFCs). This paper presents a novel signal-based diagnosis approach, based on Empirical Mode Decomposition (EMD), dedicated to PEMFCs. EMD is an empirical, intuitive, direct and adaptive signal processing method, without pre-determined basis functions. The proposed diagnosis approach relies on the decomposition of FC output voltage to detect and isolate flooding and drying faults. The low computational cost of EMD, the reduced number of required measurements, and the high diagnosis accuracy of flooding and drying faults diagnosis make this approach a promising online diagnosis tool for PEMFC degraded modes management.
\end{abstract}

\section{Introduction}

As one of the most promising clean power converter for largescale applications, polymer electrolyte membrane fuel cells (PEMFCs) present many attractive features, including high power density, high-energy conversion rate, and rapid start-up. Nevertheless, widespread commercialization still faces several challenges to extend their lifetime, increase their reliability while reducing their cost. The focus of many research programs and efforts are underway, both to develop alternative materials or designs to overcome the main technical bottlenecks, and to develop diagnosis methodologies to improve the system reliability and durability.

\footnotetext{
* Corresponding author. Tel.: +262 (0) 262 938223; fax: +262 (0) 262938673. E-mail address: michel.benne@univ-reunion.fr (M. Benne).
}

In literature, numerous PEMFC diagnosis methodologies are outlined and evaluated in terms of efficiency and applicability. Basically, diagnosis tools can be classified into two main categories: model-based and non-model based.

Model-based approaches can be sorted in three types: white, gray and black-box models. White-box models are analytical approaches, based on the computation of algebraic and/or differential equations describing the involved phenomena. Black-box models result on data-driven identification of non-physical based relationships between input/output variables. Gray-box models result on the combination of white and black-box approaches. Renowned for their high genericity and good level of accuracy on a wide range of operating conditions, white-box models are often not implementable in real-time, because of their complexity, the difficulty of estimating internal parameter values and their calculation 
time. Black-box models allow the reduction of computation time without compromising on accuracy. Admittedly, their identification strongly depends on representative data and/or human expert knowledge, which may require repeated parameters adjustment stages to increase generalization capabilities. Combining the best of both worlds, gray-box models might often represent a suitable alternative for diagnostic purposes since their offer a good trade-off between computational cost and genericity. To deal with the multiphysics and different time-scale aspects and the inherent nonlinearities, numerous model-based diagnosis approaches have been developed for PEMFC fault detection and isolation (FDI). A thorough review of model-based diagnosis methodologies for PEMFC can be consulted in Ref. [1].

With a view to help in the designing of alternative fault detection and isolation tools for PEMFC [2], have clearly indicated the relevance of three types of non-model based approaches including artificial intelligence, statistical analysis and signal processing. Artificial intelligence methods have been successfully applied to design pattern classifiers for discriminating different sorts of faults. Concerning statistical analysis, both linear and non-linear approaches have proved to be effective to develop diagnosis tools using variable dimension-reduction methods. Among the most common faults resulting from significant changes around nominal conditions, those related to water management remain a major concern. Improper water balance can lead to cell flooding or electrolyte membrane drying, which can affect PEMFCs' performance and durability. To avoid not only performance losses, but also irreversible degradations and premature aging, there is a strong need to improve flooding and drying faults diagnosis. With the aim to propose a practical comparison of diagnosis approaches [3], outlined several guidelines for the selection and design of methodologies suited to flooding and drying faults diagnosis. Based on the comparison of performance indexes and cost criteria including equipment, power consumption and computational time, this study opened up a range of new perspectives to instigate the benchmarking of methodologies for PEMFCs diagnosis. To illustrate the proposed benchmarking methodology, results of the diagnosis tool developed by Ref. [4] has been considered. This diagnosis tool combined electrochemical impedance spectroscopy (EIS) and Bayesian Networks to detect the faults, and polarization curves to classify the operating modes. Five classes have been defined: moderated drying, minor drying, light flooding, minor flooding and moderated flooding. The efficiency of the proposed diagnosis tool has been assessed on a 20 -cell $100 \mathrm{~cm}^{2}$ active area fuel cell stack. The global performance index, representative on the whole welldiagnosed samples, was about $83.3 \%$. Nonetheless, whether the methods are based on polarization curve analysis or EIS, few strategies are suitable for online implementation. Using EIS as a basis tool and a double-fuzzy method to successively extract the useful features and classify the extracted feature [5], implemented an efficient diagnosis methodology for online applications. Tested on a 20 -cell stack with an active surface area of $100 \mathrm{~cm}^{2}$, this diagnosis tool has proved to be able to easily discriminate up to five health states. As regards real-time methodologies, data-driven diagnosis has attracted increasing attention. In order to get a relevant tool to diagnose faults related to water management by analyzing cell voltage amplitudes [6,7] considered various feature extraction and classification methodologies. Among the strategies tested for a 20cell stack of $1 \mathrm{~kW}$, the association of Fisher Discrimination Analysis (FDA) and Support Vector Machine (SVM) turned out to be the best combination in terms of performance and computation cost. With intent to develop simple and inexpensive tools for real world applications [8], proved the feasibility of using wavelet-packet transform to classify states into flooded and non-flooded states [9] proposed an on-board EIS based diagnosis approach, using voltage and current signals and optimized estimation procedures. Two estimation methods have been tested: continuous wavelet transformation (CWT) and stochastic Bayesian filtering. In the latter case, on-line estimation of waveforms parameters allowed for the impedance estimation using an Extended Kalman filter, which led to an efficient approach, suitable for noise rejection. It emerged from these studies that easy to implement and computationally efficient methodologies are mandatory for the development of powerful online strategies. Nonetheless, most of those methods and algorithms have limitations. Polarization curves require quasisteady state experiments, and are unsuited to isolate the faults [3]. On the contrary, the features or signature of impedance spectra allow flooding and drying faults isolation, but valid EIS measurements require linearity, causality, stability and finiteness [5]. FFT has poor performance on transitory signals [10]. For non-stationary signals, Short Time Fourier Transform (STFT) is efficient, provided that the signals have uniform energy distribution within an analyzing window [11]. And concerning WT, reliability strongly depends on the selection of mother wavelets [12].

In this paper, a novel diagnosis approach based on Empirical Mode decomposition (EMD) is developed to diagnose flooding and drying faults. EMD has proved to be a powerful tool to analyze nonstationary signals. Besides, it does not require predetermined set of functions since it derives the basis functions from the original signal, which makes it adaptive in nature. The proposed approach has been designed to fulfill online diagnosis requirements. Indeed, the diagnosis is performed on-line on a sliding window using the PEMFC output voltage as the only measurement. Besides, contrary to some widespread diagnosis methods such as EIS-based approaches, the proposed method does not require any excitation signal or stabilization period. Therefore, the fuel cell remains continuously available to the user, even while the diagnosis is being performed. Technically and economically this method presents significant advantages in comparison to previously cited works since it is easy to implement, relies on a reduced number of required measurements and has a low computational cost.

This paper is organized as follows. The experimental setup is presented in Section 2. The third section describes the EMD-based diagnosis method. Experimental diagnosis results are given in section four. Section five addresses short-term prospects for EMD applications.

\section{Experimental description}

\subsection{Fuel cell experimental setup}

Validation tests are carried out on an experimental unit consisting of a single-cell, various monitoring and control devices, and a programmable electronic load (Fig. 1). The diagnosis method is tested using a $50 \mathrm{~W}$ single cell, made of a $50 \mathrm{~cm}^{2}$ active area membrane-electrode assembly (MEA) commercialized by Paxitech. The MEA consists of an electrolyte membrane enclosed between two electrodes and two bipolar plates. The membrane is a solid polymer film of $125 \mu \mathrm{m}$ thickness (Dupont Nafion 115). Each electrode is constituted by a carbon felt diffusion layer and a Pt-doped carbon black catalyst layer. Each bipolar plate, made of graphite, includes a 4-Serpentine flow channel.

The Supervisory Control and Data Acquisition (SCDA) system, integrated by Fuel Cell Technologies (FCT), is controlled through a proprietary GUI (graphical user interface) composed of a set of modular virtual instruments (VI) implemented with Labview graphical software tool. This makes the experimental unit a flexible environment, allowing to perform a wide range of tests based on various configuration settings: 


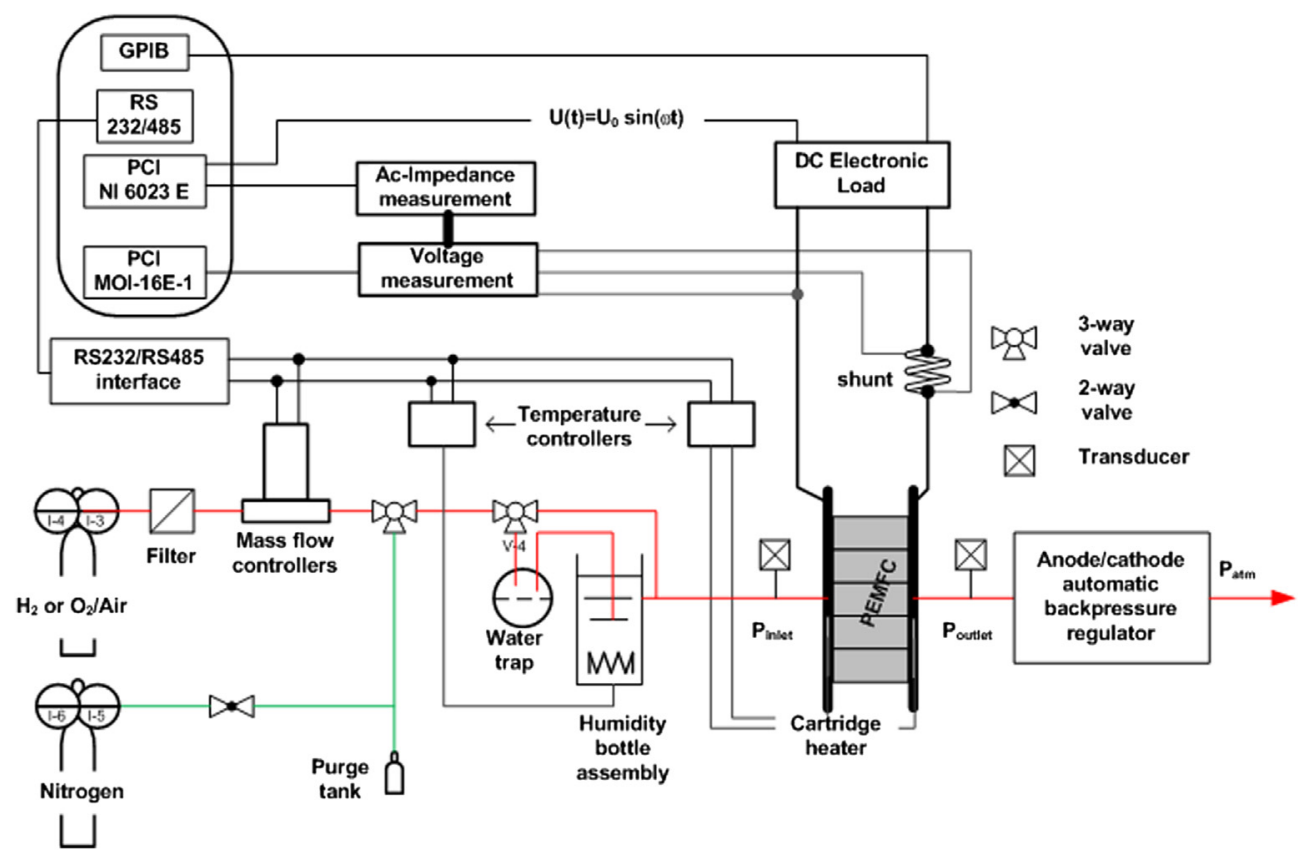

Fig. 1. Simplified process and instrumentation diagram of the system.

- fuel cell temperature, measured at cathode side,

- humidification temperatures, at the anode and cathode,

- inlet gas temperatures and mass flows, at the anode and cathode,

- and outlet back-pressures, at the anode and cathode.

In this work, pure hydrogen and air are used as fuel and oxidant, respectively.

The experimental setup, including the fuel cell system and the supervisory control and data acquisition system, is fully detailed in Refs. $[13,14]$.

\subsection{Considered faults}

The performance and durability of a fuel cell system strongly depend on both the reliability of coupled devices and numerous ancillaries, and the operating conditions, governed by multiphysics and multi-scale transport processes. Inappropriate operating conditions, and devices or ancillaries failures result in several faults [15], which most often lead to productivity, performance and reliability losses. As regards PEMFCs, water management is of vital importance [16]. Performance and reliability require a proper water balance in the cells. Without going into too much detail, liquid water in the channels and membrane dehydration, respectively leading to flooding and drying faults, may result from operating conditions, design and/or material $[5,17,18]$. In this study, healthy, flooding and drying experiments are carried out through operating conditions control.

The FC hydration level is strongly correlated to operating conditions, as cell temperature $\left(\mathrm{T}_{\text {cell }}\right)$, gas flow rates, anodic/cathotodic gas relative humidity levels $\left(\mathrm{RH}_{\mathrm{a} / \mathrm{c}}\right)$, anodic/cathotodic outlet gas pressures $\left(\mathrm{P}_{\mathrm{a} / \mathrm{c}}\right)$ and current density. The influences of these parameters on the FC hydration have been widely investigated in the literature $[19,20]$.

In this study, five parameters: anodic/cathodic relative humidity, cell temperature and air/hydrogen stoichiometry rates are selected and configured with the purpose of introducing flooding and drying out operating conditions into the stack.
Parameter values used in the sequel have been experimentally determined through trial and error method in order to ensure that healthy, flooding and drying states are reached. Healthy operating conditions are defined as follow: FC temperature is set at $70{ }^{\circ} \mathrm{C}$, anode and cathode pressures at $300 \mathrm{kPa}$, anode and cathode gases relative humidity at $80 \%$, hydrogen excess ratio at 2 , and oxygen excess ratio at 5 . Applying low oxygen excess ratio and high $\mathrm{RH}$, respectively 2 and 100\%, performs accelerated flooding experiment, and setting high oxygen excess ratio and low $\mathrm{RH}$, respectively 7 and $50 \%$, induces drying out experiment.

\section{EMD-based diagnosis approach}

In the following, a novel on-line diagnosis approach using the empirical mode decomposition (EMD) is presented to detect and isolate drying and flooding faults. Introduced by Ref. [21], EMD is an empirical, intuitive, direct and adaptive signal processing method, without pre-determined basis functions. Applied in numerous fields, from noise reduction [22] and fault diagnosis in bearings [23] to meteorology [24] and geosciences [25], this technique enables decomposing a non-periodic and non-stationary signal into a number of Intrinsic Mode Functions (IMFs). In this work, according to on-line implementation objectives, the decomposition is performed on a sliding window of $60 \mathrm{~s}$ with a sampling rate of $1 \mathrm{kHz}$.

\subsection{Empirical mode decomposition principle}

Let $s(t)$ be an oscillatory signal. As a starting point of its decomposition, oscillations are considered, at a local level, as the sum of a specified number of high and low frequency contributions called Intrinsic Mode Functions (IMFs). IMFs represent the natural oscillatory mode embedded in the signal and work as the basis functions, which makes EMD a self-adaptive method. According to the definition given by Ref. [21], an IMF should fulfill the following two conditions:

a. for a data set, the number of extrema and the number of zerocrossings must either be equal or differ at most by one. 
b. at any point, the mean value of the envelope defined by the local maxima and the envelope defined by the local minima is close to zero.

The algorithm for extracting the IMFs from the original signal $s(t)$ consists in the following steps:

1. identification of the local maxima and minima of $s(t)$ (peaks and troughs), and interpolation of these maxima and minima to generate $u(t)$ and $l(t)$, respectively the upper and the lower envelopes of $s(t)$,

2. computation of a mean signal $m(t)$, average of $u(t)$ and $l(t)$, subtraction of $m(t)$ from $s(t)$ to get a component $h_{1}(t)=s(t)-$ $m(t)$,

3. if $h_{1}(t)$ verified IMF conditions then $h_{1}(t)$ is defined as the first component of $s(t)$

4. if $h_{1}(t)$ is not an IMF, it's treated as the original signal and steps 1 . to 3 . are repeated to find the first IMF; after $k$ iterations the component $h_{1 k}(t)=h_{1(k-1)}(t)-m_{1 k}(t)$ becomes the first IMF $\operatorname{imf}_{1}(t)$,

4. separation of $i m f_{1}(t)$ from the original signal to get the residue $r_{1}(t)=s(t)-i m f_{1}(t)$

5. processing the residue $r_{1}(t)$ as an original signal and repetition of the steps 1 . to 4 . to obtain the second IMFs.

The above procedure is repeated $n$ times and such $n$ IMFs are obtained. The stopping criterion for the decomposition process is when $r_{n}(t)$ becomes a monotonic function from which no more IMF can be extracted. At the end, the original signal can be reconstructed by a linear combination of the IMFs and the final residual term $r_{n}(t)$ :

$s(t)=\sum_{i=1}^{n}\left(i m f_{i}(t)\right)+r_{n}(t)$

The successive IMFs include signal components from different frequency bands ranging from high to low frequency. Note that the number of IMFs depends on the original signal.

\subsection{EMD-based diagnosis design}

The proposed diagnosis tool is based on the computation of the energy of each IMFs to quantifying its contribution to the overall energy.

\subsubsection{Feature extraction}

The proposed methodology initially extracts feature from voltage measurements using EMD. The feature extraction method relies on the calculation of the energy contributions of the different IMFs:

1. Calculation of the energy of each IMF:

$E_{i}=\int_{-\infty}^{+\infty}\left|i m f_{i}(t)\right|^{2} d t$

2. Calculation of the total energy:

$E=\sum_{i=1}^{n} E_{i}$

3. Construction of the feature vector:

$\left[\frac{E_{1}}{E}, \frac{E_{2}}{E}, \cdots, \frac{E_{n}}{E}\right]=\left[H_{1}, H_{2}, \cdots, H_{n}\right]$

where $E_{i}$ and $H_{i}$ denote the energy and the energy contribution of the ith IMF, and $n$ is the total number of IMFs. In this study, to achieve on-line implementation, the feature extraction is performed on a sliding window of $60 \mathrm{~s}$ ( $C f$. Fig. 2).

\section{PEMFC}

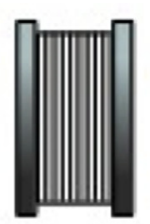

\section{Voltage measurement}

\section{DAQ and online EMD algorithm}

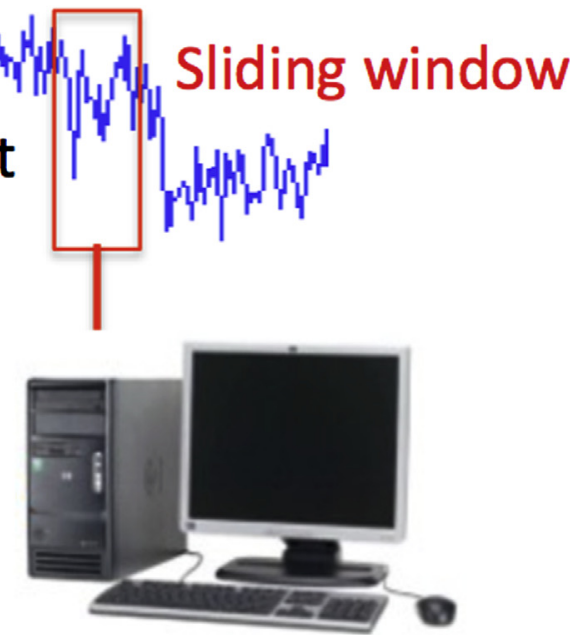

Fig. 2. Feature extraction performed on a sliding window. 
Using the EMD, fourteen intrinsic mode functions can be extracted from the output cell voltage. Fig. 3 shows the 14 IMFs obtained by the EMD of the output voltage of a healthy FC, obtained under nominal operating conditions.

\subsubsection{Feature selection}

Through this step, the dimension of the feature space is determined in order to find a satisfactory balance between the informative feature number and the computing effort for real-time implementation. In this study, the feature selection is based on experimental observations and expertise knowledge. A comparison of the different energy levels exhibits the predominance of specific modes under nominal, flooded and dried conditions. Specifically, the first and ninth IMFs turned out to be very correlated to the drying and flooding states, respectively. These observations are consistent with literature review. Indeed, flooding phenomenon only affects the low frequency loop of the impedance spectrum, which is associated to the mass transport process. Whereas the effects of drying-out phenomenon can also be observed on the high frequency loop associated with the charge transfer process [5,26 and 27]. Regarding on-line implementation objective, only the first and the ninth IMFs are used in the diagnosis approach.

\subsubsection{Diagnostic rules}

Detection and isolation of nominal, flooding and drying states are performed using the energetic contribution of the first and the ninth IMFs, $H_{1}$ and $H_{9}$ respectively:
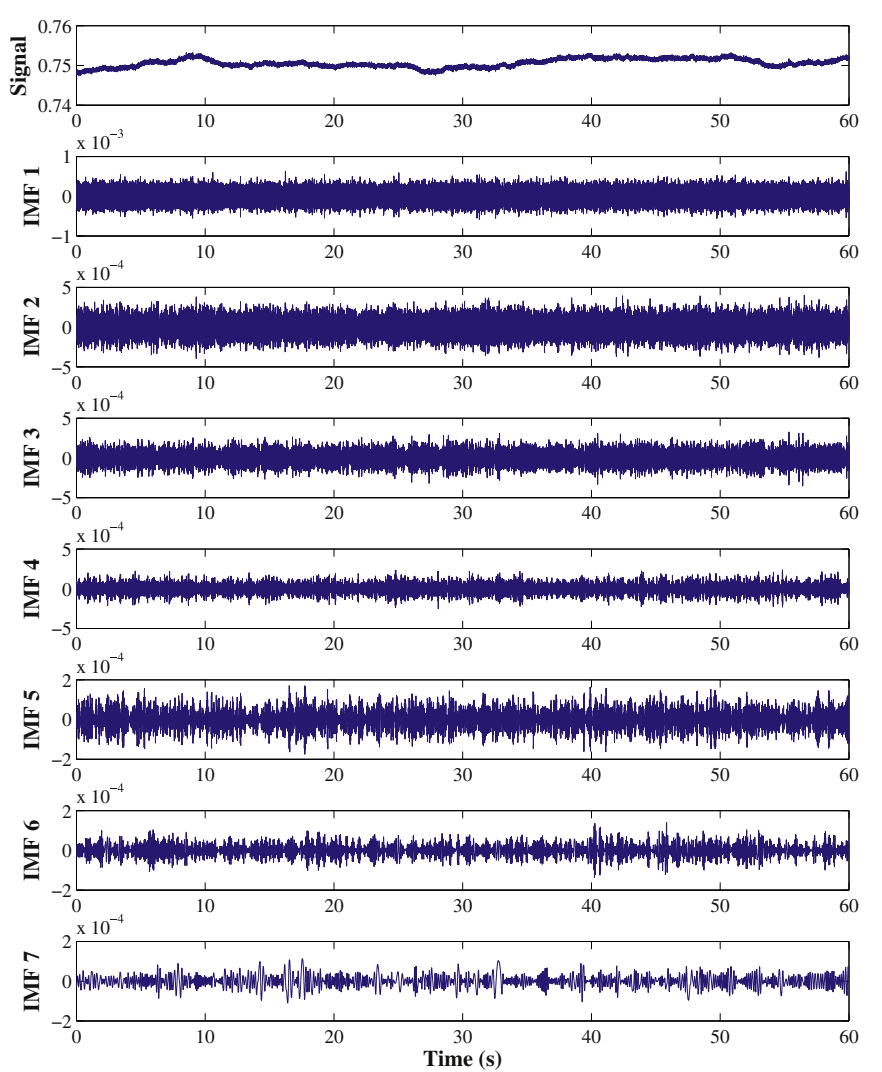

\author{
if $\left(H_{1}\right.$ is higher than a threshold DT) and $\left(H_{1}\right.$ is the highest contribution) \\ then ("Drying state") \\ elseif $\left(H_{9}\right.$ is higher than $\left.H_{1}\right)$ \\ then ("Flooding state") \\ else ("Healthy state")
}

The overall EMD-based diagnosis approach is presented in Fig. 4.

First, the fourteen IMFs are extracted on a sliding window of $60 \mathrm{~s}$ with a sampling rate of $1 \mathrm{kHz}$. Then, energy contributions of the first and ninth modes are calculated. Eventually, the state of health of the PEM is determined based on the diagnostic rules (Cf. Fig. 4). This procedure is repeated every five seconds to determine the PEMFC state of heath.

\section{Experimental results}

The performance of the proposed diagnosis method in terms of accuracy and computational cost are assessed on 861 labeled test samples, obtained under different operated conditions. The EMDbased diagnosis method, implemented in Matlab ${ }^{\circledR}$ environment, is applied on 861 windows of $60 \mathrm{~s}$. The sample numbers in healthy state, flooding state and drying state are 407, 166 and 288, respectively. In the following, the Drying Threshold DT, determined empirically based on experimental observations, is set to $15 \%$.
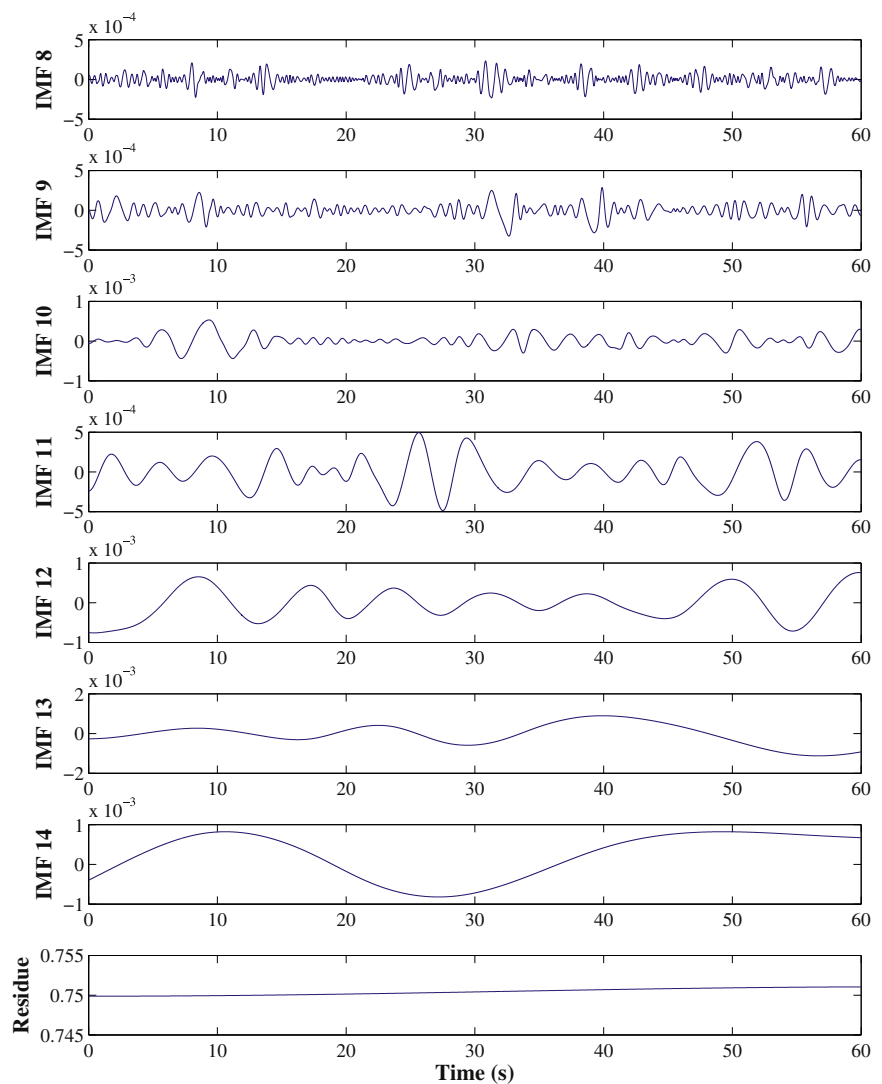

Fig. 3. EMD of fuel cell output voltage. 


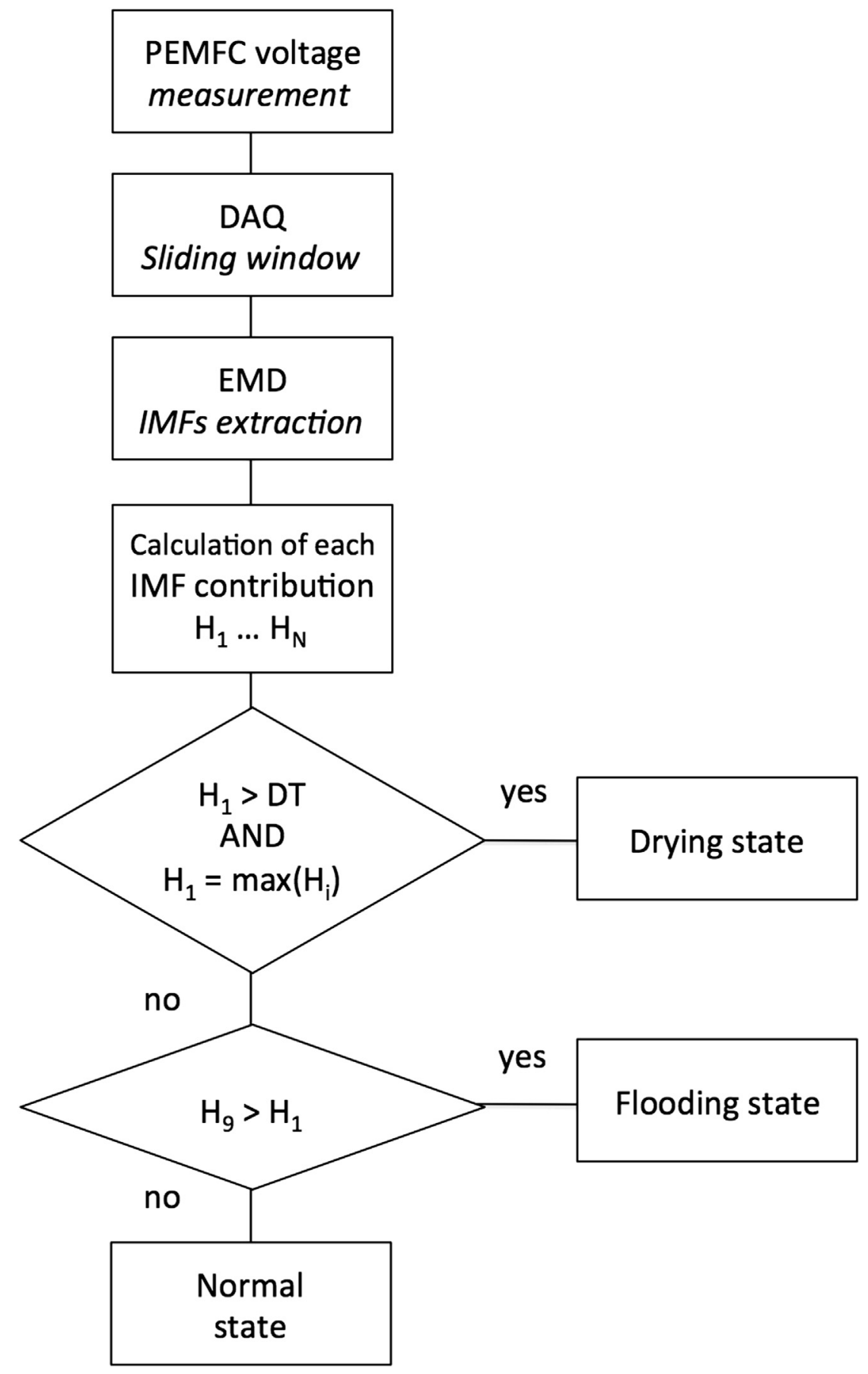

Fig. 4. Flow chart of the proposed EMD-based diagnosis strategy.

\subsection{Diagnosis accuracy}

The proposed EMD-based diagnosis method demonstrates highly satisfactory classification performance. Over the 861 test samples only 12 points have been miss-classified, which leads to a global diagnosis accuracy of $98.6 \%$.

To analyze these miss-classified points the confusion matrix of the test data are presented in Table 1. Each row represents diagnosed distribution of the data in an actual class.

Miss-classification mostly happens in the healthy class. Specifically, over the 407 samples corresponding to "healthy", seven are classified to the Flooding class and three to the Drying one.
However, it is important to emphasis that from experimental observations it is turned out that most of these miss-classifications are

Table 1

Confusion matrix of the test data.

\begin{tabular}{llll}
\hline & Diagnosed class & & Drying \\
\cline { 2 - 4 } & Healthy & Flooding & \\
\hline Actual class & & & 0.0074 \\
Healthy & 0.9754 & 0.0172 & 0 \\
Flooding & 0 & 1 & 0.9931 \\
Drying & 0.0069 & 0 & \\
\hline
\end{tabular}


located in the transition zone between the healthy state and the flooding or drying state.

\subsection{Computational costs}

The computational cost includes measurement and algorithm computation time. This aspect is a key issue since for some diagnosis tools, such as most EIS-based diagnosis methods [28], during the time that the diagnosis is performed the fuel cell becomes unavailable for the user. These methods rely on an excitation signal that required a stabilization period and a measurement duration. This could be a critical limitation for some applications such as transport. In the proposed EMD-based approach, the fuel cell remains available all the time, even while the diagnosis is being performed. Indeed, the diagnosis is based directly on cell voltage measurements and does not require any specific excitation signals. Moreover, since EMD can cope with non-stationary signals and transient phenomena no stabilization period is needed. The algorithm computational time efficiency is assessed using the mean computational time (MCT) and the maximal computational time $\left(C T_{\infty}\right)$, which is the worst case in terms of computational time:

$M C T=\frac{\sum_{i=1}^{n} C T_{i}}{n}$

$C T_{\infty}=\max _{i=1}^{n}\left(C T_{i}\right)$

where $\mathrm{n}$ is the number of trials and $C T_{i}$ the time required to perform the diagnosis at time $t=i$.

The EMD-based diagnosis approach is performed in a PC (CPU@2.7GHz, RAM@32Go, Matlab environment) and its computational time efficiency is evaluated on the 861 samples. With a mean computational time of $0.860 \mathrm{~s}$ and a maximal computational time of $0.935 \mathrm{~s}$, the proposed approach is perfectly suitable for online application.

\section{Conclusions}

In this study, a novel signal-based fault diagnosis approach has been developed to determine the state of heath of a PEMFC. This approach, based on empirical mode decomposition (EMD), only requires FC output voltage. First, the output voltage is decomposed in fourteen intrinsic mode functions (IMFs). Second, the energy of each IMFs is computed to quantifying its contribution to the overall energy. Eventually, the fault detection and isolation (FDI) of nominal, flooding and drying states are performed using only two specifics IMFs, which are the first and the ninth.

Performance of this EMD-based diagnosis approach in terms of accuracy and computational time has been experimentally assessed on a real fuel cell. In this aim, various flooding and drying scenarios have been induced. Experimental results shown that flooding and drying faults have been successfully detected from the cell voltage and isolated from the comparison of the energy contribution of the first and the ninth IMFs. Indeed, the EMD-based method has demonstrated high classification performance with global diagnosis accuracy higher than 98\%. Besides, unlike widespread diagnosis approaches such as EIS-based methods, the EMD-based approach does not require any excitation signal or stabilization period. Together with a low computational cost that makes it perfectly suitable for transport applications.

Reliant on a single online measurement, which avoids costly instrumentation, and combining low computational cost, this EMDbased fault diagnosis approach appears to be an excellent candidate for online diagnosis applications.
Further works are currently in progress to extend the range of applicability of this method, especially its application to other type of faults, such as CO poisoning.

\section{Acknowledgments}

The European Social Fund and the Réunion Region fund this work

\section{References}

[1] R. Petrone, Z. Zheng, D. Hissel, M.C. Péra, C. Pianese, M. Sorrentino, M. Becherif, N. Yousfi-Steiner, A review on model-based diagnosis methodologies for PEMFCs, Int. J. Hydrogen Energy 38 (17) (Jun. 2013) 7077-7091.

[2] Z. Zheng, R. Petrone, M.C. Péra, D. Hissel, M. Becherif, C. Pianese, N. Yousfi Steiner, M. Sorrentino, A review on non-model based diagnosis methodologies for PEM fuel cell stacks and systems, Int. J. Hydrogen Energy 38 (21) (Jul. 2013) 8914-8926.

[3] C. Cadet, S. Jemeï, F. Druart, D. Hissel, Diagnostic tools for PEMFCs: from conception to implementation, Int. J. Hydrogen Energy 39 (20) (Jul. 2014) 10613-10626.

[4] S. Wasterlain, D. Candusso, F. Harel, X. Francois, D. Hissel, Diagnosis of a fuel cell stack using electrochemical impedance spectroscopy and Bayesian Networks, in: Veh. Power Propuls. Conf. (VPPC), 2010 IEEE, 2010.

[5] Z. Zheng, M.-C. Péra, D. Hissel, M. Becherif, K.-S. Agbli, Y. Li, A double-fuzzy diagnostic methodology dedicated to online fault diagnosis of proton exchange membrane fuel cell stacks, J. Power Sources 271 (Dec. 2014) $570-581$.

[6] Z. Li, R. Outbib, S. Giurgea, D. Hissel, S. Jemeï, Online Implementation of SVM Based Fault Diagnosis Strategy for PEMFC Systems, vol. 28(21), 2014, p. 8926.

[7] Z. Li, R. Outbib, S. Giurgea, D. Hissel, Y. Li, Fault detection and isolation for polymer electrolyte membrane fuel cell systems by analyzing cell voltage generated space, Appl. Energy 148 (Jun. 2015) 260-272.

[8] N. Steiner, D. Hissel, P. Mocoteguy, D. Candusso, Non intrusive diagnosis of polymer electrolyte fuel cells by wavelet packet transform, Int. J. 36 (1) (2011) $740-746$.

[9] M. Gašperin, P. Boškoski, a. Debenjak, J. Petrovčič, Signal processing and stochastic filtering for EIS based PHM of fuel cell systems, Fuel Cells 14 (3) (Jun. 2014) 457-465.

[10] P.W. Tse, W.X. Yang, H.Y. Tam, Machine fault diagnosis through an effective exact wavelet analysis, J. Sound. Vib. 277 (4-5) (2004) 1005-1024.

[11] F.T. Yu, G. Lu, Short-time Fourier transform and wavelet transform with Fourier-domain processing, Appl. Opt. 33 (23) (1994) 5262-5270.

[12] J. Rafiee, P.W. Tse, Use of autocorrelation of wavelet coefficients for fault diagnosis, Mech. Syst. Signal Process. 23 (5) (2009) 1554-1572.

[13] C. Damour, M. Benne, C. Lebreton, J. Deseure, B. Grondin-Perez, Real-time implementation of a neural model-based self-tuning PID strategy for oxygen stoichiometry control in PEM fuel cell, Int. J. Hydrogen Energy 39 (24) (2014) $12819-12825$.

14] C. Lebreton, M. Benne, C. Damour, N. Yousfi-Steiner, B. Grondin-Perez, D. Hissel, J.-P. Chabriat, Fault tolerant control strategy applied to PEMFC water management, Int. J. Hydrogen Energy 40 (33) (2015) 10636-10646.

[15] T. Escobet, D. Feroldi, S. de Lira, V. Puig, J. Quevedo, J. Riera, M. Serra, Model-based fault diagnosis in PEM fuel cell systems. J. Power Sources 192 (1) (2009) 216-223.

[16] N. Yousfi-Steiner, P. Moçotéguy, D. Candusso, D. Hissel, A. Hernandez, A. Aslanides, A review on PEM voltage degradation associated with water management: Impacts, influent factors and characterization, J. Power Sources 183 (1) (2008) 260-274.

[17] M. Song, P. Pei, H. Zha, H. Xu, Water management of proton exchange membrane fuel cell based on control of hydrogen pressure drop, J. Powe Sources 267 (2014) 655-663.

[18] H. Li, Y. Tang, Z. Wang, Z. Shi, S. Wu, D. Song, J. Zhang, K. Fatih, J. Zhang, H. Wang Z. Liu, R. Abouatallah, A. Mazza, A review of water flooding issues in the proton exchange membrane fuel cell, J. Power Sources 178 (1) (2008) 103-117.

[19] S. Wasterlain, D. Candusso, D. Hissel, F. Harel, P. Bergman, P. Menard, M. Anwar, Study of temperature, air dew point temperature and reactant flow effects on proton exchange membrane fuel cell performances using electrochemical spectroscopy and voltammetry techniques, J. Power Sources 195 (4) (2010) 984-993.

[20] M. Ji, Z. Wei, A review of water management in polymer electrolyte membrane fuel cells, Energies 2 (4) (Nov. 2009) 1057-1106.

[21] N.E. Huang, Z. Shen, S.R. Long, M.C. Wu, H.H. Shih, Q. Zheng, N.-C. Yen, C.C. Tung, H.H. Liu, The empirical mode decomposition and the Hilbert spectrum for nonlinear and non-stationary time series analysis, Proc. R. Soc. London A 454 (1971) (1998) 903-995.

[22] H.-L. Feng, Y.-M. Fang, X.-Q. Xiang, J. Li, G.-H. Li, A data-driven noise reduction method and its application for the enhancement of stress wave signals, Sci. World J. 2012 (2012) 353081.

[23] J. Dybała, R. Zimroz, Rolling bearing diagnosing method based on empirical mode decomposition of machine vibration signal, Appl. Acoust. 77 (Mar 2014) 195-203. 
[24] R.N. Iyengar, S.T.G. Raghu Kanth, Intrinsic mode functions and a strategy for forecasting Indian monsoon rainfall, Meteorol. Atmos. Phys. 90 (1-2) (2005) $17-36$.

[25] H. Hassan, J. Peirce, Empirical mode decomposition (EMD) of potential field data: airborne gravity data as an example, SEG Expand. Abstr. 24 (2005) 704.

[26] W. Mérida, D.A. Harrington, J.M. Le Canut, G. McLean, Characterisation of proton exchange membrane fuel cell (PEMFC) failures via electrochemical impedance spectroscopy, J. Power Sources 161 (1) (2006) 264-274.

[27] N. Fouquet, C. Doulet, C. Nouillant, G. Dauphin-Tanguy, B. Ould-Bouamama, Model based PEM fuel cell state-of-health monitoring via ac impedance measurements, J. Power Sources 159 (2) (Sep. 2006) 905-913.

[28] S.M. Rezaei Niya, M. Hoorfar, Study of proton exchange membrane fuel cells using electrochemical impedance spectroscopy technique - a review, J. Power Sources 240 (2013) 281-293. 